\title{
Do testosterone supplements enhance response to phosphodiesterase 5 inhibitors in men with erectile dysfunction and hypogonadism: a systematic review and meta-analysis
}

\author{
Jun Zhu ${ }^{1 \#}$, Wei Zhang ${ }^{1 \#}$, Ningjing Ou ${ }^{1}$, Yuxuan Song ${ }^{1}$, Jiaqi Kang ${ }^{1}$, Zhen Liang ${ }^{1}$, Rui Hu ${ }^{1}$, Yongjiao Yang ${ }^{2}$, \\ Xiaoqiang Liu ${ }^{1}$ \\ ${ }^{1}$ Department of Urology, Tianjin Medical University General Hospital, Tianjin 300000, China; ${ }^{2}$ Department of Urology, Second Hospital of Tianjin \\ Medical University, Tianjin 300000, China \\ Contributions: (I) Conception and design: X Liu, W Zhang; (II) Administrative support: None; (III) Provision of study materials or patients: N Ou; (IV) \\ Collection and assembly of data: Y Song, J Kang; (V) Data analysis and interpretation: Z Liang, R Hu, Y Yang; (VI) Manuscript writing: All authors; \\ (VII) Final approval of manuscript: All authors. \\ "These authors contributed equally to this work. \\ Correspondence to: Xiaoqiang Liu. Department of Urology, Tianjin Medical University General Hospital, Tianjin 300052, China. \\ Email: tijmu126@sina.cn.
}

Background: Combining testosterone and phosphodiesterase 5 inhibitors (PDE5-Is) has become increasingly common in the treatment of men with erectile dysfunction (ED) and low testosterone levels, but combination therapy involving PDE5-Is and testosterone is highly debated, with strong reasons for and against argued by the various opinion leaders. PDE5-Is can be given prior to, alongside or after the commencement of any testosterone replacement therapy. Meanwhile, combination of PDE5-Is and testosterone is reported to better increase testosterone levels and thus improve International Index of Erectile Function (IIEF) score in hypogonadal men. The objective of this meta-analysis was to assess whether testosterone therapy (TTh) can possibly enhance the reaction to PDE5-Is in men with ED and hypogonadism.

Methods: Relevant studies and available data were extensively collected form Medline, Embase, and Cochrane Library databases until June 2019. We calculated standard mean differences (SMDs) with their 95\% confidence intervals (CIs) for IIEF including IIEF-5 and IIEF-EFD. Trial sequential analysis (TSA) was performed to explore whether the sample size of the accumulated evidence is sufficient.

Results: There were 8 studies including 913 patients. The pooled SMD of erectile function (EF) component change was 0.663 [(0.299 to 1.027$) ; \mathrm{P}<0.0001]$, which concluded that combination therapy (TTh plus PDE5-Is) is superior to PDE5-Is monotherapy group. We also conducted a subgroup analysis according to trial follow-up, baseline serum total testosterone, baseline EF score and PDE5-Is type, which may explain for the underlying source of heterogeneity in part. The frequency of adverse events and change in PSA levels did not differ between the 2 groups. None of the patients experienced an increase in the prostate specific antigen (PSA) level above $4 \mathrm{ng} / \mathrm{mL}$. Hematocrit increased significantly more in the testosterone group than in the placebo group but not greater than 0.54 .

Conclusions: In summary, the present results confirm that combination therapy is effective and safe. TTh can enhance the reaction to PDE5-Is in men with ED and hypogonadism, but this effect also depends on the specific diagnosis and initial response to PDE5-Is. Most patients with adverse events during treatment are mild, and have a stable overall safety of combination therapy.

Keywords: PDE5 inhibitors; testosterone therapy (TTh); erectile dysfunction (ED); hypogonadism; meta-analysis 
Submitted Aug 29, 2019. Accepted for publication Dec 09, 2019.

doi: $10.21037 /$ tau.2020.01.13

View this article at: http://dx.doi.org/10.21037/tau.2020.01.13

\section{Introduction}

Erectile dysfunction (ED) is a common sexual dysfunction in male patients (1). ED involves many pathophysiological mechanisms, including vascular, neurological disorder and testosterone deficiency (2). Nowadays, phosphodiesterase 5 inhibitors (PDE5-Is) is the first-line treatment for ED (3). However, approximately $30-35 \%$ of patients are ineffective while receiving PDE5-Is treatment. This is sometimes explained by associated testosterone deficiency (4).

Testosterone is considered as an important element to maintain an erection. Testosterone deficiency may affect the patient's response to PDE5-Is. In several animal models, testosterone has been reported to regulate Phosphodiesterase 5 (PDE5) and penile nitric oxide synthase, which could lead to erectile function (EF) (5-7). Weak response to PDE5-Is in patients with testosterone deficiency may be due to the relative deficiency of PDE5 (8). Late-onset hypogonadism ( $\mathrm{LOH}$ ) could be due to both testicular and hypothalamic-pituitary dysfunction (9), and $\mathrm{ED}$ is one of its main symptoms. ED in $\mathrm{LOH}$ is linked to increased oxidative stress, subclinical inflammation, and subsequent endothelial dysfunction (10). Therefore, ED and testosterone deficiency often coexist, which suggested that men with ED should routinely measure serum testosterone, and receive testosterone treatment if necessary (11-15). Meanwhile, the combination of TTh and PDE-Is has been gradually applied in men with ED and hypogonadism (16). However, effects of the combination therapy are still controversial. Spitzer et al. (17) have clearly demonstrated that in patients with ED and testosterone deficiency, combination therapy (TTh plus PDE5-Is) is not superior to PDE5-Is monotherapy group. Moreover, Buvat et al. (18) found that in patients with lower baseline of testosterone (T), effects of testosterone plus tadalafil are more significant than normal baseline of $T$. Therefore, the use of testosterone is still controversial in the treatment of men with ED and T-deficient. The objective of this meta-analysis was to assess whether TTh can enhance the response to PDE5-Is in men with ED and hypogonadism based on existing randomized controlled trials (RCTs). Trial sequential analysis (TSA) was performed to estimate required information size (RIS) to indicate firm evidence of clinical trial results and provide a termination criterion (19).

\section{Methods}

Research design kept to Preferred Reporting Items for Systematic Reviews and Meta-analyses (PRISMA) (20).

\section{Data searches}

We performed an extensive search, using PubMed (from1966-June 2019), Cochrane Library and Embase (from 1984-June 2019) using the following terms: "phosphodiesterase type 5 inhibitors" (MeSH terms) OR "phosphodiesterase type 5 inhibitors" (all fields) AND "testosterone" (MeSH terms) OR "testosterone" (all fields) AND "erectile dysfunction" (MeSH terms) OR "erectile" (all fields) AND "dysfunction" (all fields) OR "erectile dysfunction" (all fields).

\section{Trial selection}

We independently selected potential related studies and trials and then decided which RCTs to include after discussion.

Inclusion criteria used to select RCTs: (I) the subject of the study was PDE5-Is plus TTh versus PDE5-Is monotherapy for men with ED and hypogonadism or serum total testosterone $<12.1 \mathrm{nmol} / \mathrm{L}$ (21); (II) using IIEF questionnaire as a tool to evaluate EF, including IIEF-15 or IIEF-5.

Exclusion criteria used to select RCTs: (I) studies not using IIEF as primary outcome were excluded from the analysis; (II) studies using androgens other than TTh as well as studies with simultaneous treatment with other hormones and drugs were also excluded.

\section{Data extraction and bias assessment}

We selected studies that evaluated the effect of PDE5Is plus TTh on EF in men with hypogonadism by IIEF-5 or IIEF-EFD score, and we recorded T levels, the type of PDE5-Is, form of testosterone replacement, duration of treatment and side effects in all RCTs. 


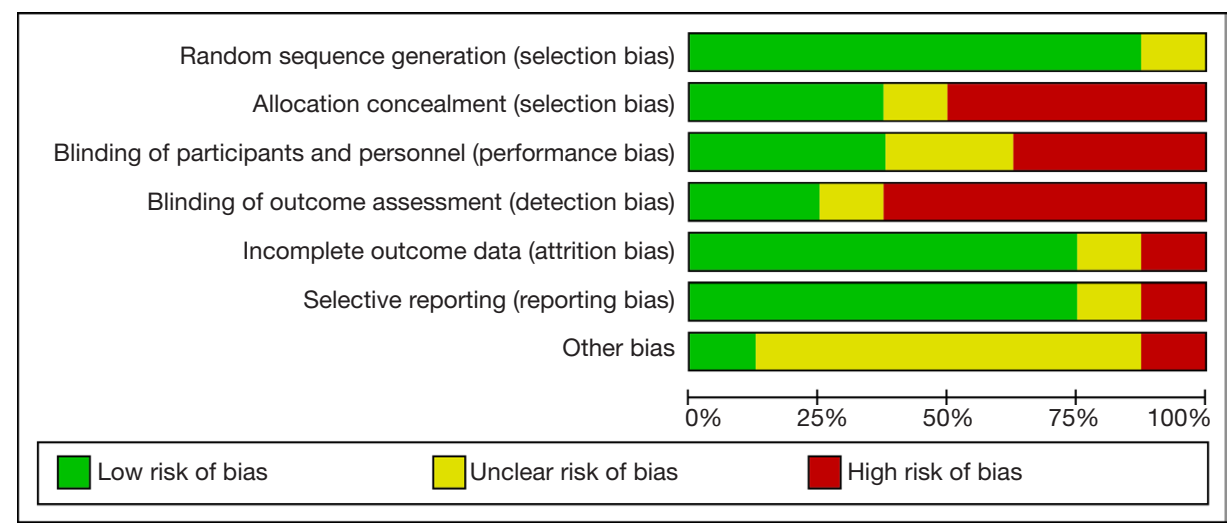

Figure 1 Methodology quality graph: review author's judgments about each methodology quality item presented as percentage across all studies.

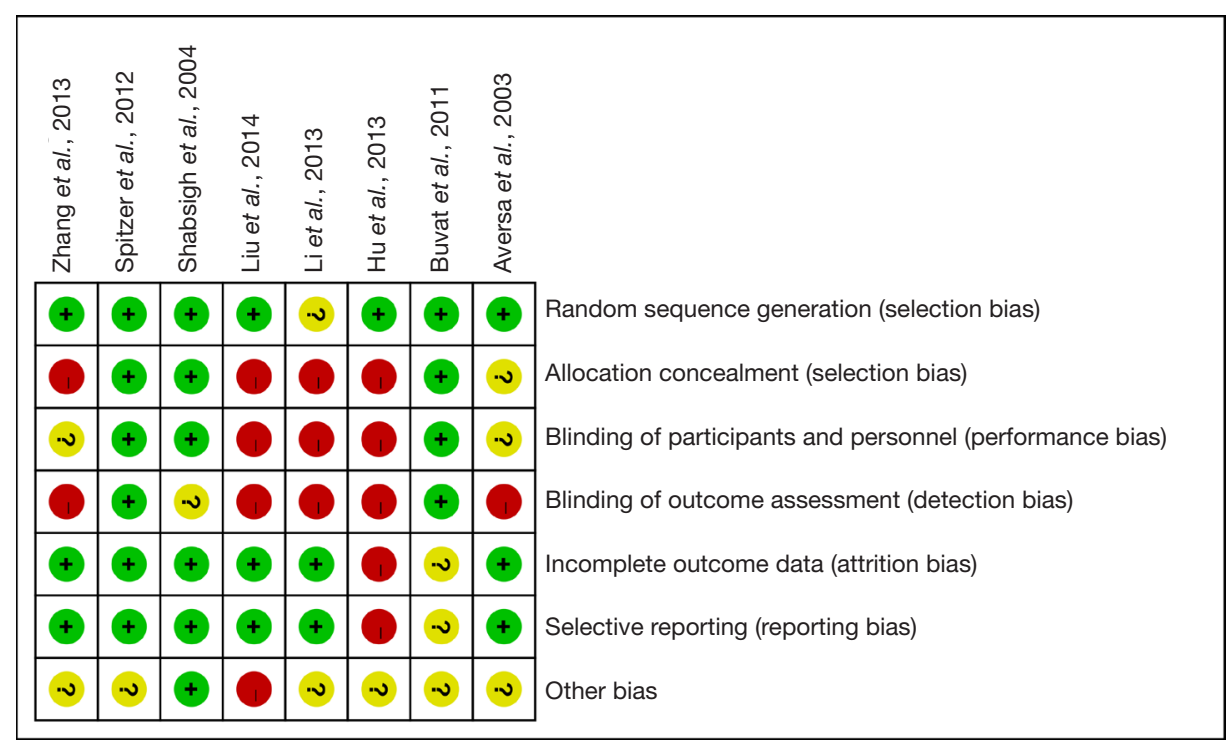

Figure 2 Methodological quality summary: review authors' judgements about each methodology quality item for each included study.

Revman software version 5.3 is applied to generate risk of bias (The Cochrane Collaboration, 2014) (22), and summarized in Figures 1,2. Two authors independently scored the items for each trial using this method.

\section{Statistical analysis}

The comparative effects of pair-wised meta-analysis were analyzed using Stata version 12.0 (Stata Corp). Heterogeneity across studies was assessed using $\mathrm{I}^{2}$ statistics. Fixed and random effect models were applied for the calculation depending on $\mathrm{I}^{2}$ statistics. Summary effect was calculated as the standard mean difference (SMD) for IIEF-5 or IIEF-EFD score, together with their $95 \%$ confidence intervals (CIs). Begg's rank correlation test and sensitivity analysis were also conducted. TSA is used to estimate the sample size of systematic reviews or meta-analysis, reducing or excluding the risk of type- 1 and type- 2 errors. TSA forms a boundary value curve by correcting the random error: the TSA threshold, and the horizontal line of $\mathrm{Z}=1.96$ is the traditional significant horizontal line $(\alpha=0.05)$. The statistical test of the meta-analysis is prompted only when the total sample size contained in the study reaches RIS, or if the $\mathrm{Z}$-curve of the hypothesis test intersects with the trial 


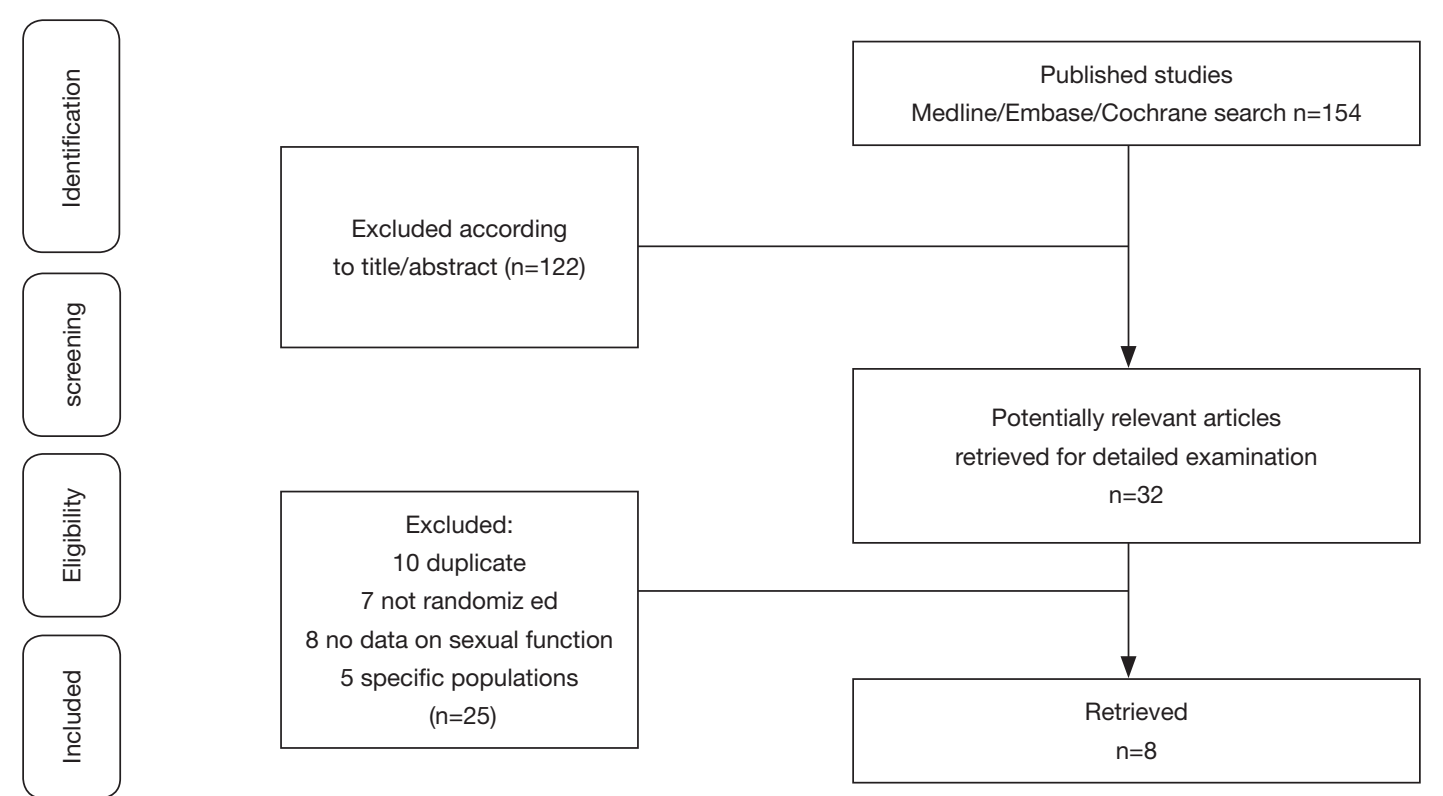

Figure 3 Methodological quality summary: review authors' judgements about each methodology quality item for each included study.

sequential boundary or the ineffective line, and considered a statistically significant effect, the result tends to be stable. Trial Sequential Analysis software (version 0.9 Copenhagen Trial Unit, Copenhagen, Denmark) is applied to a TSA for the main result $\mathrm{EF}$ (23).

\section{Results}

\section{Study characteristics}

Using the database search strategy, we excluded 146 articles for different reasons of 154 retrieved articles. The research selection process is specifically shown in Figure 3.

There were 8 studies $(17,18,24-29)$ encompassing 913 patients (with 797 patients completing the studies) with a mean follow-up of $10.8 \mathrm{wk}$ (14-8 wk). Three studies using IIEF-15 and 5 studies using IIEF-5 as their sexual function tool. Considering the different trial follow-up, baseline serum total testosterone, baseline EF score and the type of PDE5-Is would affect the final effect. We divided the included studies into different subgroups based on the above characteristics. The characteristics of trials included are summarized in Table 1.

\section{Efficacy}

Studies comparing the effect of TTh plus PDE5-Is group versus placebo plus PDE5-Is group included 913 patients.
Heterogeneity was found among the trials, $\mathrm{I}^{2}$ was 83 $(\mathrm{P}<0.0001)$. Thus, random-effect models were applied. No major publication bias was found by way of Begg's test, based on EF component change (Kendall tau 0.73, $\mathrm{P}=0.49$ ). As shown in Figure 4. We combined the results of those trials and concluded that the EF component change was much better in the combination therapy group than in the placebo plus PDE5-Is group. The pooled SMD for EF component change was 0.663 [(0.299 to 1.027$) ; \mathrm{P}<0.0001)$. Excluding each of included study for sensitivity analysis, and the change of pooled effect is not statistically significant. In addition, subgroup analysis was performed based on different baseline features, the following subgroups were defined: trial follow-up $\geq 12 \mathrm{wk}$, trial follow-up $<12 \mathrm{wk}$. Baseline serum total testosterone $>10 \mathrm{nmol} / \mathrm{L}$, serum total testosterone $\leq 10 \mathrm{nmol} / \mathrm{L}$. Baseline $\mathrm{EF}$ score $\geq 15$, EF score $<15$. The type of PDE5-Is: sildenafil, tadalafil. The pooled SMD for trial follow-up $\geq 12$ wk subgroup was 0.66 [ $(0.13$ to 1.09$)$; $\mathrm{P}<0.001]$, for trial follow-up $<12$ wk subgroup was 0.63 [ $(0.33$ to 0.93$) ; \mathrm{P}<0.001]$, for baseline serum total testosterone $>10 \mathrm{nmol} / \mathrm{L}$ subgroup was 0.42 [(-0.06 to 0.90$)$; $\mathrm{P}=0.09]$, for baseline serum total testosterone $\leq 10 \mathrm{nmol} / \mathrm{L}$ subgroup was 0.97 [ $(0.39$ to 1.55$) ; \mathrm{P}<0.001]$, for baseline EF score $\geq 15$ subgroup was 0.80 [( 0.36 to 1.23$) ; \mathrm{P}<0.001$ ], for baseline EF score $<15$ subgroup was 0.60 [(0.11 to 1.08$)$; $\mathrm{P}<0.001]$, for sildenafil subgroup was 0.38 [(0.02 to 0.75$)$; $\mathrm{P}<0.001]$, for tadalafil subgroup was 0.77 [(0.27 to 1.28$)$; 


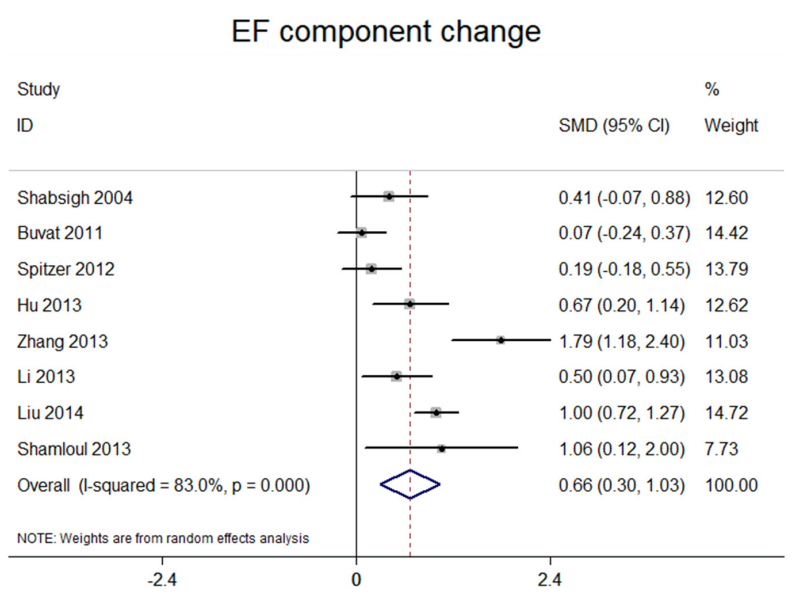

Figure 4 Forest plot for meta-analysis of the change of erectile function component for the studies on TTh plus PDE5-Is versus placebo plus PDE5-Is. PDE5-Is, phosphodiesterase 5 inhibitors.
$\mathrm{P}<0.001$, shown in Figure $5 A, B, C, D$, which may partly explain the source of heterogeneity.

\section{Safety assessment}

In the studies we included, Buvat et al. (18) reported no clinically significant differences were observed in mean PSA values between baseline ( $T$ group $0.94 \pm 0.7$, Pl group $1.36 \pm 0.92 \mathrm{ng} / \mathrm{mL}$ ) and end point ( $\mathrm{T}$ group $1.06 \pm 0.85, \mathrm{Pl}$ group $1.33 \pm 0.86 \mathrm{ng} / \mathrm{mL})$. However, according to the agespecific normal ranges, two patients had high PSA values at end point in the test group (only one case reached $4 \mathrm{ng} / \mathrm{mL}$ ). No clinically significant differences were observed in mean hematocrit values between baseline ( $\mathrm{T}$ group 46 $\pm 3.9, \mathrm{Pl}$ group $45.1 \% \pm 3.3 \%$ ) and end point ( $\mathrm{T}$ group $47.2 \pm 3.9$, $\mathrm{Pl}$ group $45.4 \% \pm 3.7 \%$ ). No hematocrit increases above

Table 1 Characteristics and outcomes of the studies included in the meta-analysis

\begin{tabular}{|c|c|c|c|c|c|c|c|c|c|}
\hline Study & $\begin{array}{l}\text { No. patients (T + PDE5- } \\
\text { Is/placebo + PDE5-Is) }\end{array}$ & $\begin{array}{l}\text { Age } \\
(y r)\end{array}$ & $\begin{array}{c}\text { Trial } \\
\text { duration } \\
\text { (wk) }\end{array}$ & $\begin{array}{c}\text { Total T level } \\
(\mathrm{nmol} / \mathrm{L})\end{array}$ & $\begin{array}{l}\text { IIEF } \\
\text { score }\end{array}$ & $\begin{array}{l}\text { Not respond to } \\
\text { initial treatment } \\
\text { with PDE5-Is } \\
\text { alone }\end{array}$ & $\begin{array}{c}\text { T form } \\
\text { and dose }\end{array}$ & $\begin{array}{l}\text { PDE5-Is } \\
\text { and dose }\end{array}$ & $\begin{array}{l}\text { Sexual } \\
\text { function } \\
\text { tool used }\end{array}$ \\
\hline $\begin{array}{l}\text { Shabsigh } \\
\text { et al., } 2004\end{array}$ & $39 / 36$ & 57.9 & 12 & 11.5 & 12.7 & Yes & $\begin{array}{c}\text { 1\% T-gel } 50 \text { mg/ } \\
\text { day }\end{array}$ & $\begin{array}{l}\text { Sildenafil (50-100 } \\
\mathrm{mg} \text { ) on demand }\end{array}$ & IIEF-15 \\
\hline $\begin{array}{l}\text { Spitzer } \\
\text { et al., } 2012\end{array}$ & $70 / 70$ & 54.9 & 14 & 12.3 & 12.1 & No & $\begin{array}{c}\text { 1\% T-gel } 100 \mathrm{mg} / \\
\text { day }\end{array}$ & $\begin{array}{l}\text { Sildenafil (50-100 } \\
\text { mg) on demand }\end{array}$ & IIEF-15 \\
\hline $\begin{array}{l}\text { Hu et al., } \\
2013\end{array}$ & $60 / 60$ & 51.9 & 12 & 9.8 & 13.1 & No & $\begin{array}{l}\text { Oral undecanoate } \\
80 \mathrm{mg} \text { bid }\end{array}$ & $\begin{array}{l}\text { Tadalafil } 10 \mathrm{mg} \\
\text { daily }\end{array}$ & IIEF-5 \\
\hline $\begin{array}{l}\text { Shamloul } \\
\text { et al., } 2013\end{array}$ & $10 / 10$ & 56 & 8 & 7.3 & 15.4 & Yes & $\begin{array}{l}\text { Oral undecanoate } \\
120 \mathrm{mg} / \text { day }\end{array}$ & $\begin{array}{l}\text { Sildenafil (50-100 } \\
\text { mg) on demand }\end{array}$ & IIEF-5 \\
\hline $\begin{array}{l}\text { Liu et al., } \\
2014\end{array}$ & $117 / 118$ & 45.2 & 8 & 6.9 & 8.9 & No & $\begin{array}{c}\text { Oral undecanoate } \\
80 \mathrm{mg} \text { bid }\end{array}$ & $\begin{array}{c}\text { Tadalafil } 5 \mathrm{mg} \\
\text { daily }\end{array}$ & IIEF-5 \\
\hline
\end{tabular}

T, testosterone; No, number; PDE5-Is, phophodiesterase-5 inhibitors; IIEF, International Index of Erectile Function. 


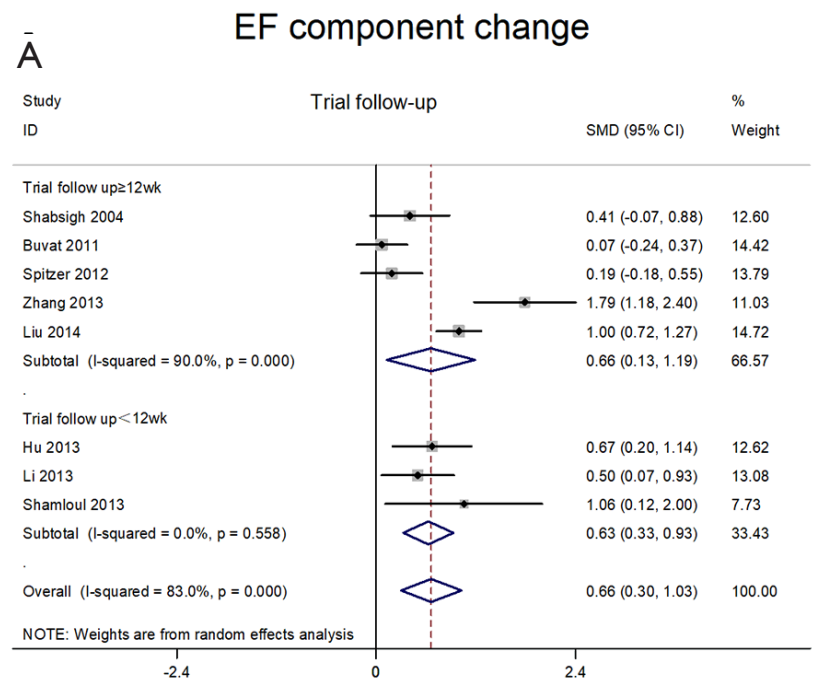

\section{B EF component change}

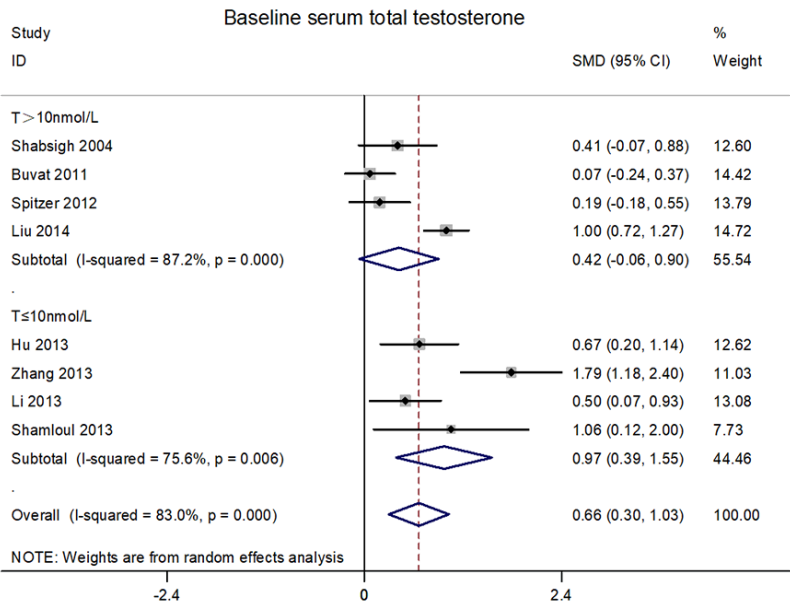

C

EF component change

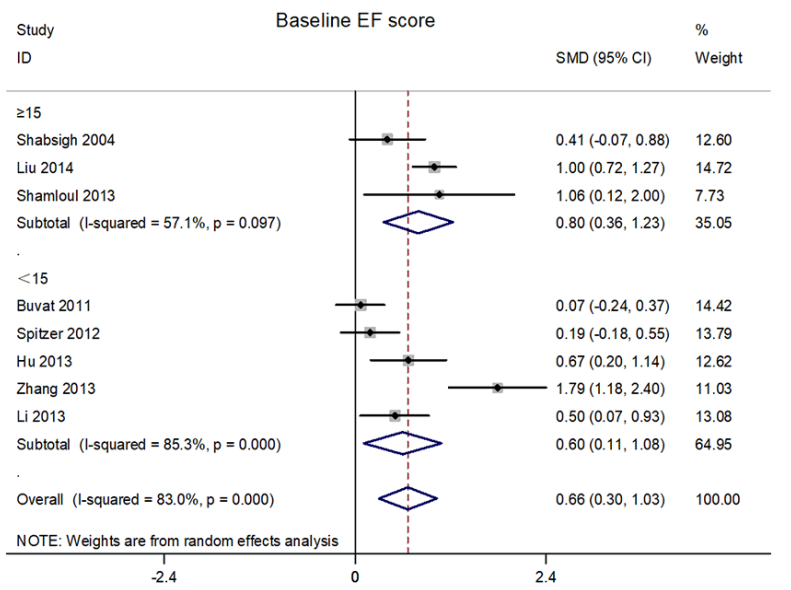

EF component change

D

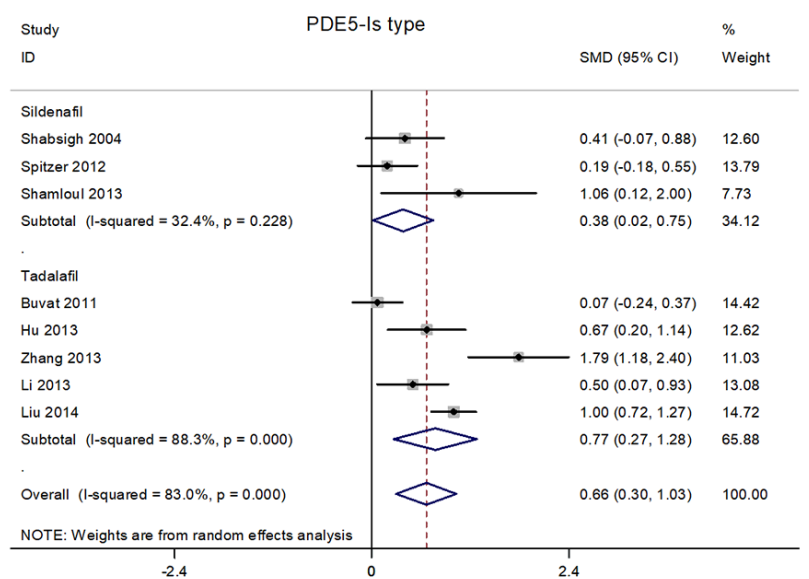

Figure 5 Forest plot for meta-analysis of the change of erectile function component at trial follow-up $\geq 12$ wk (upper panel) and trial followup $<12$ wk (lower panel) (A), baseline serum total testosterone $>10 \mathrm{nmol} / \mathrm{L}$ (upper panel) and serum total testosterone $\leq 10 \mathrm{nmol} / \mathrm{L}$ (lower panel) (B), baseline EF score $\geq 15$ (upper panel) and trial EF score <15 (lower panel) (C), sildenafil (upper panel) and tadalafil (lower panel) (D).

$52 \%$ was observed at endpoint. And Spitzer et al. (17) showed that hematocrit increased significantly more in the testosterone group than in the placebo group $(\mathrm{P}=0.011)$ but not greater than 0.54 , and the frequency of adverse events and change in PSA levels did not differ between the two groups. None of the patients suffered from an increase in the PSA level above $4 \mathrm{ng} / \mathrm{mL}$. Similar results were reported in the remaining included studies. All studies did not find serious adverse events, so that testosterone treatment didn't need to be stopped, especially no prostate cancer. During the course of treatment, no significant hormonal changes were found except for the increase of androgen levels.

\section{Trial sequential analyses}

TSA was performed to estimate RIS to indicate firm evidence of clinical trial results, EF component change, which is shown in Figure 6; Although the RIS of 1,534 was not reached, Z-curve crossed two boundary, the expected conclusions are obtained in advance so that firm 


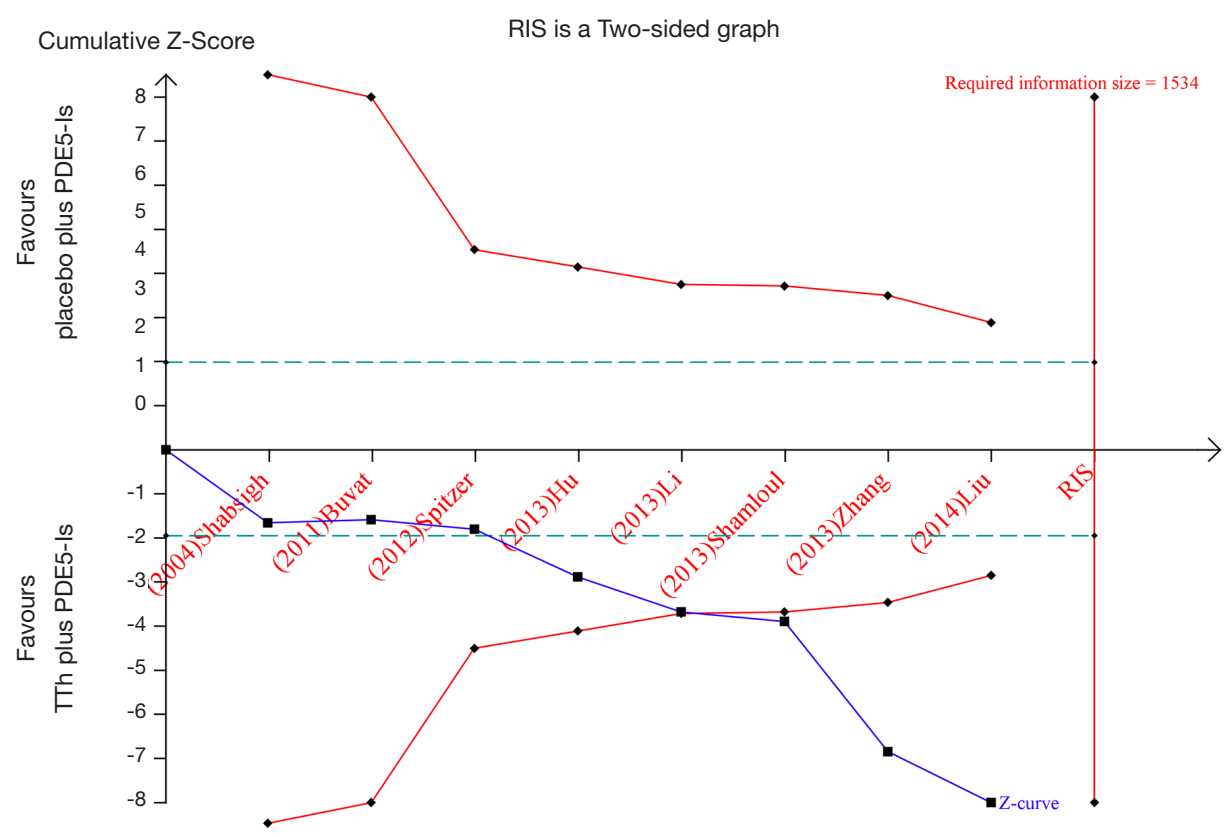

Figure 6 Trial sequential analysis for the comparison of TTh plus PDE5-Is versus placebo plus PDE5-Is, included in the all-studies metaanalysis. PDE5-Is, phosphodiesterase 5 inhibitors.

evidence was reached and that testosterone supplements can enhance the response to PDE5-Is in men with ED and hypogonadism.

\section{Discussion}

This meta-analysis confirms that TTh increase PDE5-inhibitor responses in EF in man with ED and hypogonadism. After implement subgroup analysis, we conclude that baseline serum testosterone levels and baseline EF scores may affect the final outcome of IIEF. The effect of TTh plus PDE5-Is in man with ED is more significant in patients with lower baseline $\mathrm{T}$ levels. It is noteworthy that after summarizing the study of baseline T levels $>10 \mathrm{nmol} / \mathrm{L}$, also $<12.1 \mathrm{nmol} / \mathrm{L}$, we found that combination therapy was not superior to PDE5-Is plus placebo in improving EF component which confirm that combination therapy will show different results in different clinical situations. Spitzer et al. showed that after run-in period of sildenafil, serum testosterone increases $3.47 \mathrm{nmol} / \mathrm{L}$. This approach has been supported by many other studies, men with ED can improve their testosterone levels after restoring sexual activity. Moreover, when PDE5-Is treatment has restored sexual function, there is no need to add testosterone treatment if it is for the treatment of other complications of hypogonadism
(30-32), including in subclinical hypogonadism, which may be caused by lack of sexual activity (33). Therefore, PDE5Is treatment can avoid unnecessary testosterone treatment in spite of the increased testosterone levels after PDE5-Is treatment are limited $(17,30,32)$. Serum testosterone levels is difficult to achieve normal levels simply by increasing the sexual activity of a young man with extremely low testosterone levels. In addition, PDE5-Is alone may have a less effect on hypogonadism that have a clear cause. Among the studies we included $(18,27,29)$, patients who were less effective during run-in period of PDE5-Is were selected, add testosterone therapy (TTh) achieved a significant result. Many young hypogonadal men suffering ED because of the lack of testosterone, and TTh alone is sufficient to improve EF (34-36). Besides, studies have shown that PDE5-Is is less effective in treating T-deficient people (6). Related studies have shown that man with ED and lower serum testosterone levels, who have failed treatment with PDE5-Is, TTh improves their clinical response to PDE5-Is $(17,18,29)$.

In summary, the effect of combination therapy with $T$ plus PDE5-Is for men with erectile dysfunction and hypogonadism probably depends on the specific diagnosis and patient response to PDE5-Is. For older men with ED, their $\mathrm{T}$ deficiency is often without clinical symptoms and 
may simply be due to a lack of sexual activity. Therefore, combination therapy (T plus PDE5-Is) should not be considered as a routine treatment (37). However, serum testosterone levels are difficult to achieve normal levels simply by increasing the sexual activity of a young man with extremely low testosterone levels, and PDE5-Is alone may have a less effect in men with subclinical hypogonadism which have a clear cause (38), who may benefit from combination therapy (T plus PDE5-Is).

We evaluated the safety of testosterone treatment in each study. All studies did not experience serious side effects, so that testosterone treatment needs to be stopped, especially no prostate cancer. During the course of treatment, no significant hormonal changes were found except for the increase of androgen levels.

No evidence exists that TTh increases prostate cancer risk in men with testosterone-deficiency (39). Many metaanalyses indicated that there was no significant increase in prostate cancer or development of PSA levels greater than $4.0 \mathrm{ng} / \mathrm{mL}$ in men treated with TTh versus placebo $(40,41)$. In 2004, Kaufman and Graydon (42) reported no prostate cancer recurrences in 7 men with TTh after radical prostatectomy (RP). Median follow-up in the study was 2 years, with the longest follow-up of 12 years. Agarwal and Oefelein (43) reported no recurrences in 10 testosterone deficient men with history of RP who received TTh for up to 19 months, however, there are certain clinical scenarios in which several specialty society and expert group guideline statements indicate caution or contraindication to TTh $(11,15,21)$. Presence of prostate cancer, particularly metastatic prostate cancer, 101 has historically been considered a contraindication to TTh. Several guideline statements still consider this to be a contraindication $(15,21)$ including men at increased risk for developing prostate cancer-based upon the presence of a palpable nodule or elevated prostate specific antigen (PSA) $(44,45)$.

There are some limitations in this study: including low-evidence, heterogeneous studies. Different studies have different definitions of baseline testosterone levels, and studies have not performed run-in period, lead to greater heterogeneity. In addition, small sample size may lead to casual results. A larger sample size of prospective, well-designed trials is needed to better identify target populations that may benefit from the combination therapy.

\section{Conclusions}

In conclusion, the present results confirm that combination therapy is effective. For older men with ED, their T deficiency is often without clinical symptoms. Therefore, combination therapy should not be considered as a routine treatment. And young man with ED and subclinical hypogonadism with extremely low testosterone levels, may benefit from combination therapy. Besides, the effect of combination therapy in man with ED and lower baseline testosterone levels is more significant. Most patients have a stable overall safety of combination therapy.

\section{Acknowledgments}

Funding: Zhao Yi-Cheng Medical Science Foundation. ZYYFY2018031.

\section{Footnote}

Conflicts of Interest: All authors have completed the ICMJE uniform disclosure form (available at http://dx.doi. org/10.21037/tau.2020.01.13). The authors have no conflicts of interest to declare.

Ethical Statement: The authors are accountable for all aspects of the work in ensuring that questions related to the accuracy or integrity of any part of the work are appropriately investigated and resolved.

Open Access Statement: This is an Open Access article distributed in accordance with the Creative Commons Attribution-NonCommercial-NoDerivs 4.0 International License (CC BY-NC-ND 4.0), which permits the noncommercial replication and distribution of the article with the strict proviso that no changes or edits are made and the original work is properly cited (including links to both the formal publication through the relevant DOI and the license). See: https://creativecommons.org/licenses/by-nc$\mathrm{nd} / 4.0 /$.

\section{References}

1. Impotence. NIH Consens Statement 1992;10:1-33.

2. Shamloul R, Ghanem H. Erectile dysfunction. Lancet 2013;381:153-65.

3. Qaseem A, Snow V, Denberg TD, et al. Hormonal testing and pharmacologic treatment of erectile dysfunction: a clinical practice guideline from the American College of Physicians. Ann Intern Med 2009;151:639-49.

4. Lau DH, Kommu S, Mumtaz FH, et al. The management 
of phosphodiesterase-5 (PDE5) inhibitor failure. Curr Vasc Pharmacol 2006;4:89-93.

5. Filippi S, Vignozzi L, Morelli A, et al. Testosterone partially ameliorates metabolic profile and erectile responsiveness to PDE5 inhibitors in an animal model of male metabolic syndrome. J Sex Med 2009;6:3274-88.

6. Morelli A, Filippi S, Mancina R, et al. Androgens regulate phosphodiesterase type 5 expression and functional activity in corpora cavernosa. Endocrinology 2004;145:2253-63.

7. Zhang XH, Morelli A, Luconi M, et al. Testosterone regulates PDE5 expression and in vivo responsiveness to tadalafil in rat corpus cavernosum. Eur Urol 2005;47:40916; discussion 416.

8. Morelli A, Filippi S, Zhang XH, et al. Peripheral regulatory mechanisms in erection. Int J Androl 2005;28 Suppl 2:23-7.

9. Golan R, Scovell JM, Ramasamy R. Age-related testosterone decline is due to waning of both testicular and hypothalamic-pituitary function. Aging Male 2015;18:201-4.

10. Condorelli RA, Calogero AE, Vicari E, et al. Endothelial progenitor cells and erectile dysfunction: a brief review on diagnostic significance and summary of our experience. Aging Male 2013;16:29-32.

11. Bhasin S, Cunningham GR, Hayes FJ, et al. Testosterone therapy in men with androgen deficiency syndromes: an Endocrine Society clinical practice guideline. J Clin Endocrinol Metab 2010;95:2536-59.

12. Guay AT, Spark RF, Bansal S, et al. American Association of Clinical Endocrinologists medical guidelines for clinical practice for the evaluation and treatment of male sexual dysfunction: a couple's problem--2003 update. Endocr Pract 2003;9:77-95.

13. Hatzimouratidis K, Amar E, Eardley I, et al. Guidelines on male sexual dysfunction: erectile dysfunction and premature ejaculation. Eur Urol 2010;57:804-14.

14. Montorsi F, Adaikan G, Becher E, et al. Summary of the recommendations on sexual dysfunctions in men. J Sex Med 2010;7:3572-88.

15. Wang C, Nieschlag E, Swerdloff R, et al. Investigation, treatment and monitoring of late-onset hypogonadism in males: ISA, ISSAM, EAU, EAA and ASA recommendations. Eur J Endocrinol 2008;159:507-14.

16. Khera M, Bhattacharya RK, Blick G, et al. Improved sexual function with testosterone replacement therapy in hypogonadal men: real-world data from the Testim Registry in the United States (TRiUS). J Sex Med 2011;8:3204-13.
17. Spitzer M, Basaria S, Travison TG, et al. Effect of testosterone replacement on response to sildenafil citrate in men with erectile dysfunction: a parallel, randomized trial. Ann Intern Med 2012;157:681-91.

18. Buvat J, Montorsi F, Maggi M, et al. Hypogonadal men nonresponders to the PDE5 inhibitor tadalafil benefit from normalization of testosterone levels with a $1 \%$ hydroalcoholic testosterone gel in the treatment of erectile dysfunction (TADTEST study). J Sex Med 2011;8:284-93.

19. Imberger G, Thorlund K, Gluud C, et al. False-positive findings in Cochrane meta-analyses with and without application of trial sequential analysis: an empirical review. BMJ Open 2016;6:e011890.

20. Moher D, Liberati A, Tetzlaff J, et al. Preferred reporting items for systematic reviews and meta-analyses: the PRISMA statement. PLoS Med 2009;6:e1000097.

21. Mirone V, Debruyne F, Dohle G, et al. European Association of Urology Position Statement on the Role of the Urologist in the Management of Male Hypogonadism and Testosterone Therapy. Eur Urol 2017;72:164-7.

22. Collaboration TC. Cochrane Handbook for systematic reviews of interventions version 5.1.0. 2014. Available online: http://ims.cochrane.org/revman. (Accessed 01/04/2019).

23. Wetterslev J, Thorlund K, Brok J, et al. Estimating required information size by quantifying diversity in random-effects model meta-analyses. BMC Med Res Methodol 2009;9:86.

24. Hu EP. Efficacy of testosterone undecanoate combined with PDE5 inhibitors in the treatment of patients over 40 years old with erectile dysfunction. Zhonghua Nan Ke Xue 2013;19:1048-50.

25. Li GY, Liang JH, Meng ZB, et al. Low-dose testosterone undecanoate capsules combined with tadalafil for lateonset hypogonadism accompanied with ED. Zhonghua Nan Ke Xue 2013;19:630-3.

26. Liu HB, Kong CZ, Zhao W. Efficacy of testosterone undecanoate capsules combined with tadalafi for patients with erectile dysfunction and low testosterone levels. Zhonghua Nan Ke Xue 2014;20:854-7.

27. Shabsigh R, Kaufman JM, Steidle C, et al. Randomized study of testosterone gel as adjunctive therapy to sildenafil in hypogonadal men with erectile dysfunction who do not respond to sildenafil alone. J Urol 2004;172:658-63.

28. Zhang ZH, Ma HB. Clinical study of tadalafil combined with testosterone undecanoate in the treatment of men with ED and testosterone deficiency. Zhonghua Nan Ke Xue 2013;19:1138-9.

29. Shamloul R, Ghanem H, Fahmy I, et al. Testosterone 
therapy can enhance erectile function response to sildenafil in patients with PADAM: a pilot study. J Sex Med 2005;2:559-64.

30. Carosa E, Benvenga S, Trimarchi F, et al. Sexual inactivity results in reversible reduction of $\mathrm{LH}$ bioavailability. Int $\mathrm{J}$ Impot Res 2002;14:93-9; discussion 100.

31. Carosa E, Martini P, Brandetti F, et al. Type V phosphodiesterase inhibitor treatments for erectile dysfunction increase testosterone levels. Clin Endocrinol (Oxf) 2004;61:382-6.

32. Jannini EA, Screponi E, Carosa E, et al. Lack of sexual activity from erectile dysfunction is associated with a reversible reduction in serum testosterone. Int J Androl 1999;22:385-92.

33. Balercia G, Boscaro M, Lombardo F, et al. Sexual symptoms in endocrine diseases: psychosomatic perspectives. Psychother Psychosom 2007;76:134-40.

34. Allan CA, Forbes EA, Strauss BJ, et al. Testosterone therapy increases sexual desire in ageing men with lownormal testosterone levels and symptoms of androgen deficiency. Int J Impot Res 2008;20:396-401.

35. Cavallini G, Caracciolo S, Vitali G, et al. Carnitine versus androgen administration in the treatment of sexual dysfunction, depressed mood, and fatigue associated with male aging. Urology 2004;63:641-6.

36. Chiang HS, Hwang TI, Hsui YS, et al. Transdermal testosterone gel increases serum testosterone levels in hypogonadal men in Taiwan with improvements in sexual function. Int J Impot Res 2007;19:411-7.

37. Aversa A, Francomano D, Lenzi A. Does testosterone

Cite this article as: Zhu J, Zhang W, Ou N, Song Y, Kang J, Liang Z, Hu R, Yang Y, Liu X. Do testosterone supplements enhance response to phosphodiesterase 5 inhibitors in men with erectile dysfunction and hypogonadism: a systematic review and meta-analysis. Transl Androl Urol 2020;9(2):591-600. doi: 10.21037/tau.2020.01.13 supplementation increase PDE5-inhibitor responses in difficult-to-treat erectile dysfunction patients? Expert Opin Pharmacother 2015;16:625-8.

38. Giannetta E, Gianfrilli D, Barbagallo F, et al. Subclinical male hypogonadism. Best Pract Res Clin Endocrinol Metab 2012;26:539-50.

39. Khera M, Crawford D, Morales A, et al. A new era of testosterone and prostate cancer: from physiology to clinical implications. Eur Urol 2014;65:115-23.

40. Calof OM, Singh AB, Lee ML, et al. Adverse events associated with testosterone replacement in middleaged and older men: a meta-analysis of randomized, placebo-controlled trials. J Gerontol A Biol Sci Med Sci 2005;60:1451-7.

41. Shabsigh R, Crawford ED, Nehra A, et al. Testosterone therapy in hypogonadal men and potential prostate cancer risk: a systematic review. Int J Impot Res 2009;21:9-23.

42. Kaufman JM, Graydon RJ. Androgen replacement after curative radical prostatectomy for prostate cancer in hypogonadal men. J Urol 2004;172:920-2.

43. Agarwal PK, Oefelein MG. Testosterone replacement therapy after primary treatment for prostate cancer. J Urol 2005;173:533-6.

44. Thompson IM, Ankerst DP, Chi C, et al. Assessing prostate cancer risk: results from the Prostate Cancer Prevention Trial. J Natl Cancer Inst 2006;98:529-34.

45. Thompson IM, Pauler DK, Goodman PJ, et al. Prevalence of prostate cancer among men with a prostate-specific antigen level $<$ or $=4.0 \mathrm{ng}$ per milliliter. $\mathrm{N}$ Engl $\mathrm{J}$ Med 2004;350:2239-46. 